\title{
SARCOLEMMAL DEFICIENCY OF SARCOGLYCAN COMPLEX IN AN 18-MONTH-OLD TURKISH BOY WITH A LARGE DELETION IN THE BETA SARCOGLYCAN GENE
}

\author{
Diniz $\mathrm{G}^{1, *}$, Tekgul $\mathrm{H}^{2}$, Hazan $\mathrm{F}^{3}$, Yararbas $\mathrm{K}^{4}$, Tukun $\mathrm{A}^{5}$
}

\begin{abstract}
*Corresponding Author: Associate Professor Gulden Diniz, Neuromuscular Disease Center, Tepecik Research Hospital, Kibris Sehitleri Cad. 51/11 Alsancak 35220, Izmir, Turkey. Tel: +90-232-362-5547. Fax: +90-232-3627144. E-mail: agdiniz@gmail.com
\end{abstract}

\begin{abstract}
Limb-girdle muscular dystrophy type 2E (LGMD-2E) is caused by autosomal recessive defects in the beta sarcoglycan $(S G C B)$ gene located on chromosome $4 \mathrm{q} 12$. In this case report, the clinical findings, histopathological features and molecular genetic data in a boy with $\beta$ sarcoglycanopathy are presented. An 18-month-old boy had a very high serum creatinine phosphokinase (CPK) level that was accidentally determined. The results of molecular analyses for the dystrophin gene was found to be normal. He underwent a muscle biopsy which showed dystrophic features. Immunohistochemistry showed that there was a total loss of sarcolemmal sarcoglycan complex. DNA analysis revealed a large homozygous deletion in the $S C G B$ gene. During 4 years of follow-up, there was no evidence to predict a severe clinical course except the muscle enzyme elevation and myopathic electromyography (EMG) finding. The presented milder phenotype of LGMD-2E with a large deletion in the $S G C B$ gene provided additional
\end{abstract}

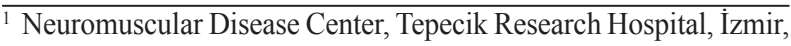
Turkey

${ }^{2}$ Department of Pediatric Neurology, Ege University, Faculty of Medicine, İzmir, Turkey

${ }^{3}$ Department of Medical Genetics, Dr. Behcet Uz Children's Research Hospital, İzmir, Turkey

${ }^{4}$ Department of Medical Genetics, Duzen Laboratories, Istanbul, Turkey

${ }^{5}$ Department of Medical Genetics, Duzen Laboratories, Ankara, Turkey
}

support for the clinical heterogeneity and pathogenic complexity of the disease.

Keywords: Beta sarcoglycan $(S G C B)$ gene; Large deletion; Muscular dystrophy (MD)

\section{INTRODUCTION}

Limb girdle muscular dystrophy type 2E (LG$\mathrm{MD}-2 \mathrm{E}$ ) is an autosomal recessive muscular disease caused by genetic defects in the beta sarcoglycan $(S G C B)$ gene. The $S G C B$ gene, which encodes instructions for making the $\beta$ subunit of the sarcolemmal proteins called the sarcoglycans (SGCs), located on chromosome 4q12 [1,2]. $\beta$ Sarcoglycan ( $\beta$-SGC), one of the four SGCs, is essential for membrane integrity during muscle contraction and provides a scaffold for important signaling molecules [1-3]. The LGMD-2E predominantly affects proximal muscles around the scapular and the pelvic girdles and has a very heterogeneous phenotype. The age of onset, rate of progression and the severity of disease can vary between and also within affected families [1-4].

Complex mechanisms have been postulated for the development of the clinical heterogenity of LGMD-2E. A mutation in any $S G C$ gene can lead to a reduction of the other SGCs [4-8]. The sarcoglycan-sarcospan and dystroglycan complexes were disrupted in skeletal, cardiac and smooth muscle membranes. It is suggested that the $S G C B$ gene must first be evaluated if there is a total absence of SGCs [4]. Here we present a milder phenotype of LGMD-2E with a large deletion in the $S G C B$ gene, which pro- 
vides additional support for the clinical heterogeneity and complex pathogenicity of the disease.

Case Report. A 12-month-old boy had an increased serum creatine phosphokinase (CPK) without symptoms. Persistent elevation of CPK values prompted muscle biopsy at 18 months of age. He had second degree consanguineous parents from Turkey without an ancestral history of neuromuscular disorders. Cognitive and motor development was normal. Deep tendon reflexes were present and he had no contractures. He started walking at 14 months of age and was walking normally. Pulmonary function tests were normal. His CPK levels were between 9000 and $11,000 \mathrm{U} / \mathrm{L}$ (normal $<250 \mathrm{U} / \mathrm{L}$ ), and there was evidence of myopathy on electromyography (EMG). Because of the persistent high CPK level, muscular dystrophy (MD) was suspected and, after informed consent, samples were obtained for histopathology, immunohistochemistry and molecular genetics testing.

The histopathological evaluation was performed on the biopsy from the gastrocnemius muscle. The biopsy specimen was frozen in isopentane that was pre-cooled to $-160{ }^{\circ} \mathrm{C}$ in liquid nitrogen. Cryosections were immunostained for dystrophin using a polyclonal antibody (Neomarkers-PA137587; Thermo Scientific, Waltham, MA, USA), with a monoclonal spectrin antibody (Novocastra-SPECT; Leica Biosystems, Wetzlar, Germany) as a control. The SGCs were detected with anti $\alpha-, \beta-, \delta$ - and $\gamma$ - SGC antibodies (Novocastra-A,B,D OR G-SARC-CE). The muscle biopsy showed dystrophic changes such as contraction, regeneration, degeneration, necrosis, nuclear internalization and fibrosis (Figure 1). Im-

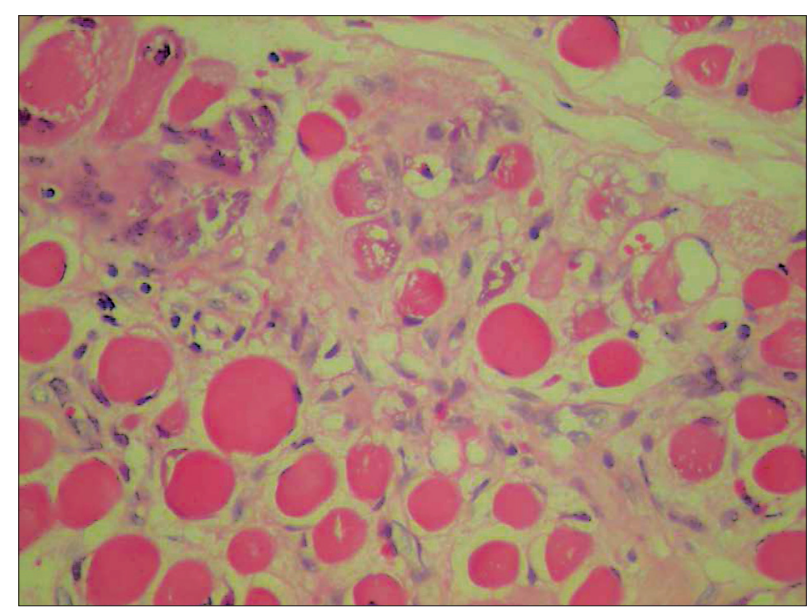

Figure 1. Differences in the size and shape of myofibers and marked fibrosis as well as regeneration. munohistochemically, sarcolemmal dystrophin and spectrin expressions were present at normal levels, whereas sarcolemmal $\alpha-, \beta-, \delta$ - and $\gamma$-SGCs were diffusely absent or there was abnormal sarcoplasmic staining in some myofibers (Figure 2).

Genomic DNA was extracted from the remnant muscle tissue using a commercial DNA extraction kit (QiaGen; Qiagen Inc., Valencia, CA, USA) following the standard manufacturer's protocol. The concentration of sample DNA was determined by a Nanodrop ${ }^{\circledR}$ spectrophotometer (NanoDrop Technologies, Wilmington, DE, USA). The exon regions and flanking short intronic sequences of the $S G C A, S G C B, S G C D$ and $S G C G$ genes were amplified using polymerase chain reaction (PCR), followed by direct sequencing of the PCR products (Applied Biosystems, Foster City, CA, USA). The multiplex ligation-dependent probe amplification (MLPA) technique (Applied Systems), was used for deletion and duplication analysis for all four SGCs. Based on analysis of the proband, we have identified a large deletion in the $S G C B$ gene (Figure 3). In addition, there was a heterozygous c. G860A (p.S287N) mutation in the $S G C G$ gene that was not a disease-causing genetic defect. The results of the molecular analyses for mutations of dystrophin, $\alpha-, \beta$ - and $\delta$-SGC genes were normal.

\section{DISCUSSION}

By somatic cell hybridization and fluorescence in situ hybridization (FISH), it was proved that the $S G C B$ gene contains six exons and is located on chromosome $4 \mathrm{q} 12$ [1-3]. The $\beta$-SGC, protein product of the $S G C B$ gene, localizes at the sarcolemma and is expressed ubiquitously, although predominantly, in muscle. The $S G C B$ gene defects cause LGMD-2E, which may also be a severe or mild clinical phenotype. Calf hypertrophy may be present. It was reported that there are Amish patients with $\beta$ sarcoglycanopathy who are still ambulant in the fifth decade. In addition, LGMD-2E primarily affects skeletal muscles, while brain, peripheral nerve and cardiac function are largely preserved. The less severe cardiac dysfunction in patients with LGMD-2E was explained by the lesser expression of $\beta$-SGC in cardiac muscle [1,3,5-9]. Differing expression patterns of sarcoglycan components in heart and skeletal muscle could be the result of alternatively spliced transcripts in these tissues. Hitherto, only rare $S G C B$ 


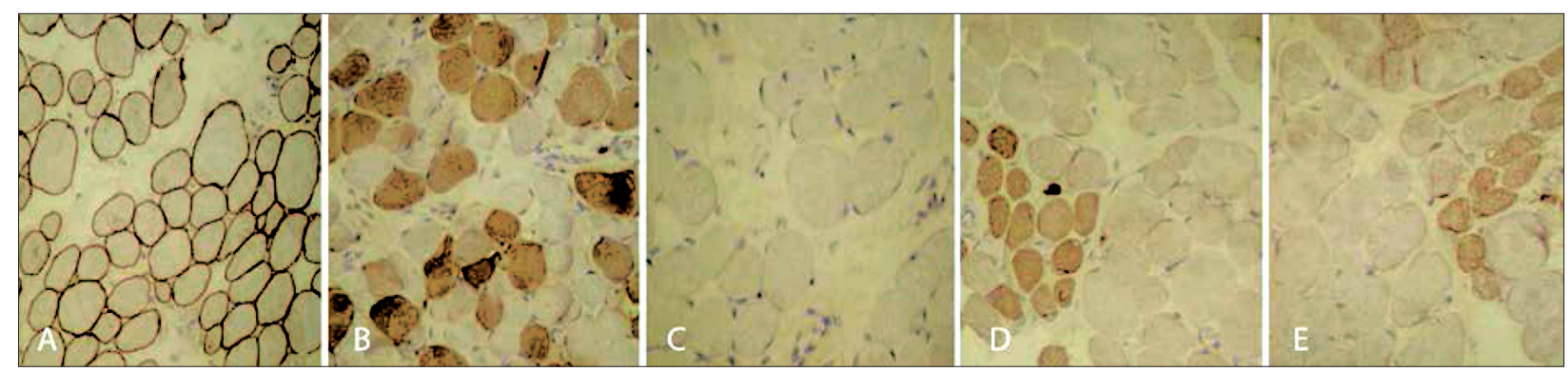

Figure 2. Normal sarcolemmal expression of dystrophin (A) diffuse sarcolemmal absence and/or abnormal sarcoplasmic expressions of $S G C A(\mathrm{~B}), S G C B(\mathrm{C}), S G C D(\mathrm{D})$ and $S G C G(\mathrm{E})$.

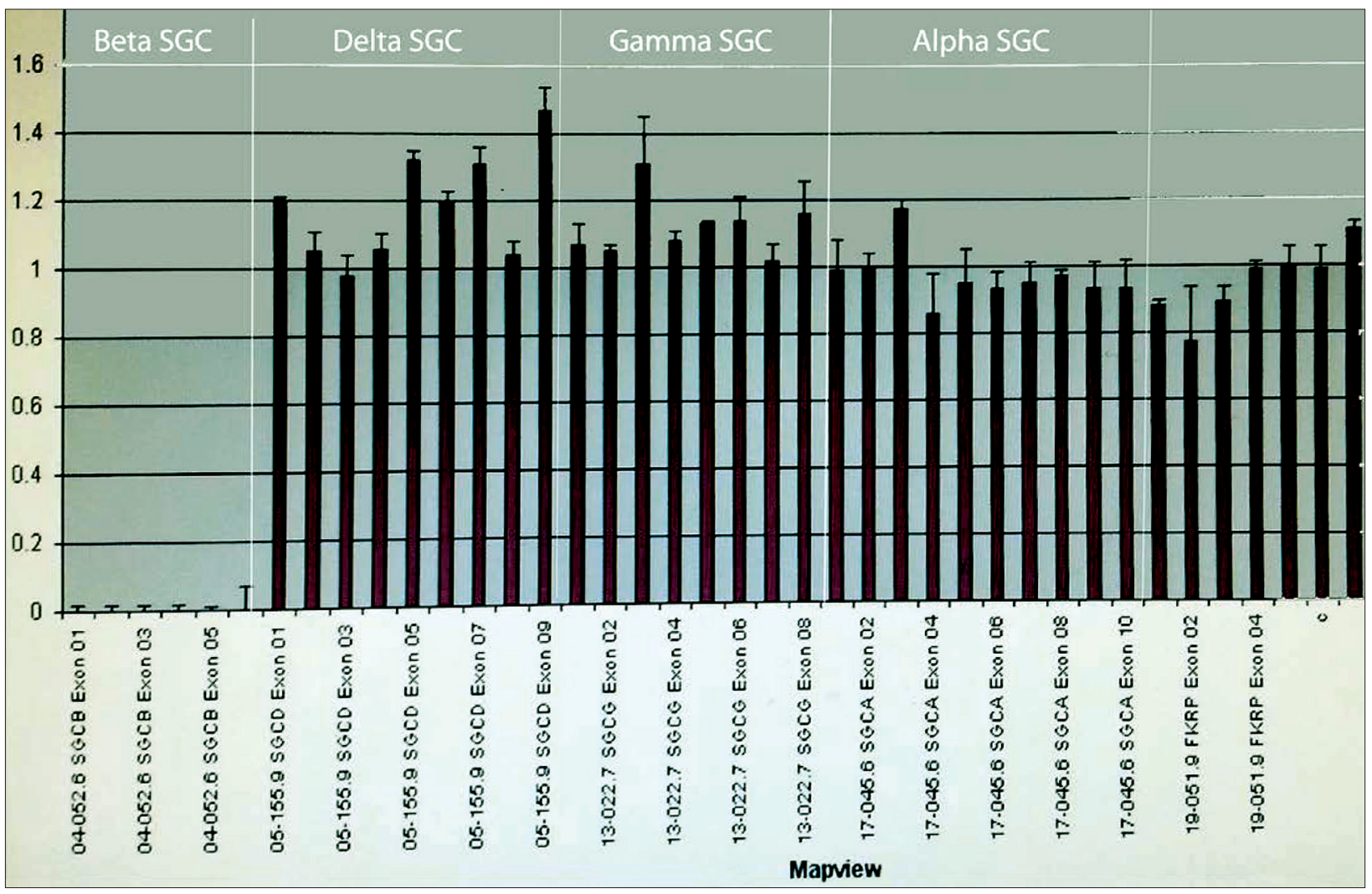

Figure 3. The large homozygous deletion of the proband in exons 1 through 6.

gene mutations causing cardiomyopathy have been reported $[6,9]$. We did not find any clinical evidence of cardiac involvement, decreased intellectual capacity or neuropathy demonstrated by electromyography in the patient described in this report.

Immunohistochemical analysis of sarcolemmal proteins in muscle biopsy is an important part of the diagnostic evaluation of patients with MD. Reduced or absent sarcolemmal expression of one of the four SGCs can be found in patients with any type of LGMDs and also in patients with dystrophinopathies. It has previously been suggested that different patterns of SGC expression could predict the primary genetic defect, and that genetic analysis could be directed by these patterns [2,7-11]. However, Klinge et al. [12] reported that residual SGC expression could be highly variable and an accurate prediction of the genotype could not be achieved. Bonnemann et al. [4] also determined that the total loss of sarcolemmal SGCs was caused by defects in the $S G C B$ gene. Therefore they recommended using antibodies against all four SGCs for immune analysis of skeletal muscle sections $[1,4,7,8,12]$. Similarly, a concomitant reduction in dystrophin and any of the SGCs may illustrate the importance of considering coexisting dystrophinopathies in patients with sarcoglycandeficient LGMD [1-3]. For this reason, it is not easy 
to decide whether the disease is a dystrophinopathy with defective expressions of SGCs or an LGMD with defective expression of dystrophin $[1,7,8,10,12,13]$. However, in the patient described in this report, expression of sarcolemmal dystrophin and molecular analysis of the dystrophin gene were diffusely normal and thus dystrophinopathies were ruled out.

Araishi et al. [5] also reported that deficiency of $\beta$-SGC caused loss of all other sarcoglycans as well as loss of sarcospan in the sarcolemma. The authors concluded that $\beta$-SGC is an important protein for formation of the sarcoglycan complex and it may be to strengthen the dys-trophin axis connecting the basement membrane with the cytoskeleton. It is interesting to note that, despite total SGCs loss, patients could have mild to moderate clinical courses at least to their current ages [9]. In the reported case, we determined the expression defects of all four sar-colemmal proteins. Moreover, the expressions of other sarcolemmal proteins such as dystrophin, merosin, dystroglycans were normal. In addition, during 4 years of follow-up, there was no evidence to predict a severe clinical course except the muscle enzyme elevation and myopathic EMG finding.

In summary, this report describes a large deletion of the $S G C B$ gene, which causes the total loss of sarcolemmal SGC proteins and further emphasizes the importance of systematic analysis of all related genes, instead of limiting the analysis to the one $S G C$ gene that is hypothesized to be the cause of the abnormalities. In this case report, we also highlight the complexity of staining patterns associated with sarcolemmal proteins and the importance of careful analysis of this staining pattern in order to narrow the differential diagnosis of muscular dystrophies.

Declaration of Interest. The authors report no conflicts of interest. The authors alone are responsible for the content and writing of this article.

\section{REFERENCES}

1. Dubowitz V, Sewry CA, Oldfors A, Eds. Muscular dystrophies and allied disorders II: Limbgirdle muscular dystrophies. Muscle Biopsy: A Practical Approach. Philadelphia, PA: Saunders/ Elsevier. 2013: 276-302.

2. Lim LE, Duclos F, Broux O, Bourg N, Sunada Y, Allamand V, et al. Beta-sarcoglycan: Charac- terization and role in limb-girdle muscular dystrophy linked to 4q12. Nat Genet. 1995; 11(3): 257-265.

3. Sandona D, Betto R. Sarcoglycanopathies: Molecular pathogenesis and therapeutic prospects. Expert Rev Mol Med. 2009; 11: e28. doi: 10.1017/S146239940900 1203.

4. Bonnemann CG, Modi R, Noguchi S, Mizuno Y, Yoshida M, Gussoni E, et al. Beta-sarcoglycan (A3b) mutations cause autosomal recessive muscular dystrophy with loss of the sarcoglycan complex. Nat Genet. 1995; 11(3): 266-273. Erratum: Nat Genet. 1996; 12(1): 110.

5. Araishi K, Sasaoka T, Imamura M, Noguchi S, Hama H, Wakabayashi E, et al. Loss of the sarcoglycan complex and sarcospan leads to muscular dystrophy in beta-sarcoglycan-deficient mice. Hum Molec Genet. 1999; 8(9): 1589-1598.

6. Barresi R, Di Blasi C, Negri T, Brugnori R, Vitali A, Felisari G, et al. Disruption of heart sarcoglycan complex and severe cardiomyopathy caused by beta sarcoglycan mutations. J Med Genet. 2000; 37(2): 102-107.

7. Diniz G, Tosun Yildirim H, Akinci G, Hazan F, Ozturk A, Yararbas K, et al. Sarcolemmal alpha and gam-ma sarcoglycan protein deficiencies in Turkish siblings with a novel missense mutation in the alpha sarcoglycan gene. Pediatr Neurol. 2014; 50(6): 640-647.

8. Diniz G, Tosun Yildirim H, Gokben S, Serdaroglu G, Hazan F, Yararbas K, et al. Concomitant alpha- and gamma-sarcoglycan deficiencies in a Turkish boy with a novel deletion in the alphasarcoglycan gene. Case Rep Genet. 2014; 2014: 248561. doi: 10.1155/2014/248561.

9. Dincer P, Akcoren Z, Demir E, Richard I, Sancak $\mathrm{O}$, Kale $\mathrm{G}$, et al. A cross section of autosomal recessive limb-girdle muscular dystrophies in 38 families. J Med Genet. 2000; 37(5): 361-367.

10. Pogue R, Anderson LV, Pyle A, Sewry C, Pollitt C, Johnson MA, et al. Strategy for mutation analysis in the autosomal recessive limb-girdle muscular dystrophies. Neuromuscul Disord. 2001; 11(1): 80-87.

11. Moreira ES, Vainzof M, Suzuki OT, Pavanello RC, Zatz M, Passos-Bueno MR. Genotype-phenotype correlations in 35 Brazilian families with 
sarcoglycanopathies including the description of three novel mutations. J Med Genet. 2003; 40(2): E12. doi: 10.1136/jmg.40.2.e12.

12. Klinge L, Dekomien G, Aboumousa A, Charlton R, Epplen JT, Barresi R, et al. Sarcoglycanopathies: Can muscle immunoanalysis predict the genotype? Neuromuscul Disord. 2008; 18(12): 934-941.

13. Trabelsi M, Kavian N, Daoud F, Commere V, Deburgrave N, Beugnet C, et al. Revised spectrum of mutations in sarcoglycanopathies. Eur J Hum Genet. 2008; 16(7): 793-803. 
